\title{
The canonical Wnt signal paradoxically regulates osteoarthritis development through the endochondral ossification process
}

\author{
Hiroshi Kawaguchi* \\ The Chief of the Spine Center, Japan Community Health Care Organization (JCHO), Tsukudo 5-1, Tokyo 162-8543, Japan
}

Osteoarthritis, a joint disorder characterized by cartilage degradation and osteophyte formation, is considered a major public health issue causing chronic disability worldwide with the increasing number of aging people today [1,2]. Although the social impact of this disorder has been compared to osteoporosis, [3] osteoarthritis is far behind osteoporosis in the development of disease-modifying treatments. This is mainly because little is known about the underlying molecular mechanism which can be the therapeutic target. Recent animal studies have disclosed that osteoarthritis is initiated by production of proteinases such as matrix metalloproteinases (MMPs) and aggrecanases that sever type II collagen (COL2) and proteoglycan, the principal matrix of articular cartilage [4-6]. However, trials applying the proteinase inhibitors for clinical use as a disease-modifying treatment have to date been unsuccessful due to insufficient efficiency and severe adverse events, $[7,8]$ turning the interest of researchers to the upstream signals of the proteinases in chondrocytes. Cartilage matrix proteins, especially undegraded COL2, are shown to induce proteinases through a receptor tyrosine kinase discoidin domain receptor 2 (DDR2) [9-11]. This causes the degradation of the matrix proteins, and the product fragments then induce proteinases through integrins $\alpha 2 \beta 1$ and $\alpha 5 \beta 1$ [9]. Another possible signal is pro-inflammatory factors like prostaglandins, tumor necrosis factor- $\alpha$ (TNF- $\alpha$ ), interleukin-1 (IL$1)$, IL-6, and nitric oxides that are produced mainly by synovial cells, similarly to rheumatoid arthritis [12]; however, accumulating evidence using experimental osteoarthritis models in knockout mice has not supported that these factors play a central role in the pathogenesis of osteoarthritis $[13,14]$.Our previous study also showed that levels of TNF- $\alpha$, IL-1 and IL-6 in the synovial fluid from knee joints of osteoarthritis patients were much lower than those from patients with rheumatoid arthritis [15].

Endochondral ossification including chondrocyte maturation and apoptosis is an essential process for skeletal development and growth at the embryonic cartilage and growth plate cartilage, respectively, but should not occur under physiological conditions in the joint cartilage which is a permanent cartilage and is not destined to be replaced by bone. Recently, chondrocyte maturation has been implicated to be deeply involved in the pathogenesis of osteoarthritis. In articular cartilage of osteoarthritis patients, pathologic expression of type $\mathrm{X}$ collagen (COL10) and other differentiation markers, including annexin VI, alkaline phosphatase, osteopontin, and osteocalcin, have been reported, [16-20] indicating that the osteoarthritis articular cartilage cannot maintain the characteristics of the permanent cartilage, but adds those of the embryonic or growth plate cartilage. A mouse genetic study found the induction of Runx2, an essential transcription factor for chondrocyte hypertrophy, [21,22] in articular chondrocytes during osteoarthritis progression under mechanical stress, which led to cartilage degradation and osteophyte formation through the chondrocyte maturation and MMP production $[23,24]$. Carminerin, an inducer of chondrocyte calcification, [25] is also reported to contribute to osteophyte formation during the osteoarthritis progression by studies on the deficient mice [26]. In addition to chondrocyte maturation, chondrocyte apoptosis has also recently been reported to be involved in osteoarthritis development [27]. Intraarticular injection of a pancaspase inhibitor suppresses cartilage degradation under osteoarthritis induction in rabbits [28]. Osteoprotegerin (OPG) is also suggested to prevent osteoarthritis progression through functional inhibition of its ligand TNF-related apoptosis-inducing ligand (TRAIL) [29].

The canonical Wnt- $\beta$-catenin signal, a potent regulator of skeletal development and homeostasis of adult bone mass, [30] is also known to induce chondrocyte maturation. During skeletal development and growth, activation of the Wnt- $\beta$-catenin signal in chondrocytes in limb buds or growth plates stimulates hypertrophy, calcification, and expressions of MMP and vascular endothelial growth factor [31-33]. The inhibition of Dickkopf-1 (Dkk1), a negative regulator of the Wnt$\beta$-catenin signal, has been reported to allow conversion of a mouse model of rheumatoid arthritis to osteoarthritis, indicating a regulation of joint remodeling [34]. Furthermore, recent human genomic studies have demonstrated that polymorphisms in the $F r z B$ gene encoding the secreted frizzled-related protein 3 (sFRP3), an extracellular inhibitor of the Wnt- $\beta$-catenin signal, is associated with an increased susceptibility to osteoarthritis [35-37]. The polymorphisms were at least partly associated with a reduced ability to limit $\beta$-catenin signaling. Increased levels of $\beta$-catenin have been reported in chondrocytes within areas of degenerative cartilage $[38,39]$. These suggest a possible involvement of $\beta$-catenin in the pathogenesis of osteoarthritis $[40,41]$.

Zhu et al. for the first time provide direct evidence of the role of $\beta$-catenin in the development of osteoarthritis [42]. They created mutant mice using an elegant breeding scheme by crossing mice floxed for exon 3 of $\beta$-catenin with cartilage specific and tamoxifen

Correspondence to: The Chief of the Spine Center, Japan Community Health Care Organization (JCHO), Tsukudo 5-1, Tokyo 162-8543, Japan, Tel: 090-30025156; Fax: 03-3260-7840; E-mail: kawaguchi0126@gmail.com

Key words: osteoarthritis, wnt, $\beta$-catenin, cartilage, osteoarthritis, endochondral ossification

Received: May 02, 2016; Accepted: May 23, 2016; Published: May 27, 2016 
regulated Cre mice to produce mice with a stabilized $\beta$-catenin protein resistant to phosphorylation by GSK-3 $\beta$. The conditional activation of $\beta$-catenin in articular chondrocytes of adult mice caused osteoarthritis-like cartilage degradation and osteophyte formation, and this was associated with accelerated chondrocyte maturation and MMP expressions. Interestingly, the authors recently reported that selective suppression of $\beta$-catenin signaling in articular chondrocytes also causes osteoarthritis-like cartilage degradation in Col2a1-ICAT (inhibitor of $\beta$-catenin and $\mathrm{T}$ cell factor) transgenic mice, and this was mediated by enhancement of apoptosis of the chondrocytes [43]. These seem somewhat contradictory since both gain- and loss-of-functions of $\beta$-catenin in articular cartilage exhibited a similar osteoarthritislike phenotype, although the underlying mechanisms were different. Under physiological conditions, $\beta$-catenin may maintain the moderate maturation of articular chondrocytes, which is consistent with the role in skeletal development and growth, and prevent apoptosis. Both excessive and insufficient $\beta$-catenin levels may therefore impair the homeostasis of articular chondrocytes by enhancing pathological maturation and apoptosis, respectively, both of which are endochondral ossification processes.

The figure summarizes the hypothesis of the mechanism whereby $\beta$-catenin regulates osteoarthritis development. $\beta$-catenin induces chondrocyte maturation similarly to Runx2, whereas it suppresses chondrocyte apoptosis similarly to OPG. The proteinases produced during the endochondral ossification process cause cartilage degradation at the center of the joint and osteophyte formation at the periphery. The difference of the two sites may depend on the vascularity. At the periphery, vascularity is accessible from the synovium or tendon, which completes endochondroal ossification and forms osteophytes, just as it does at the embryonic and growth plate cartilage. However, in the center, the vascularity is not accessible from the edge, so that it may end up with cartilage degradation without being replaced by bone.

As described by the authors, the Wnt- $\beta$-catenin signal and the related molecules may regulate the osteoarthritis development through an endochondral ossification process including chondrocyte

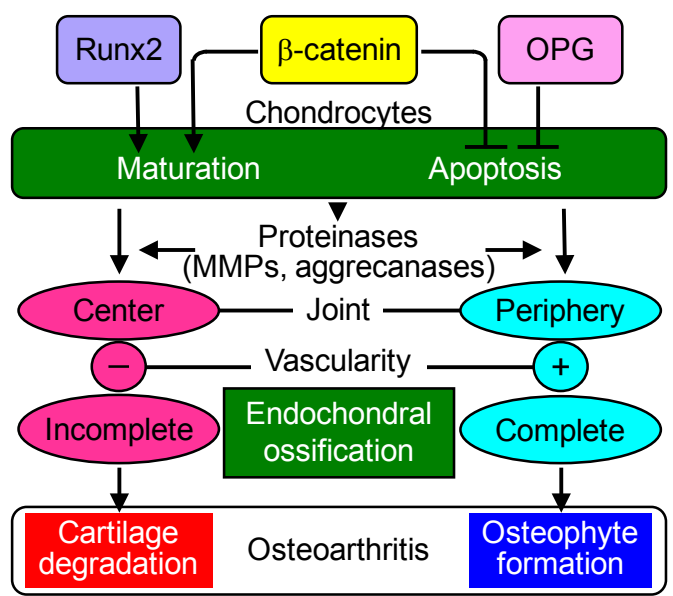

Figure 1: Possible mechanism underlying the regulation of cartilage degradation and osteophyte formation by $\beta$-catenin. $\beta$-catenin induces chondrocyte maturation and suppresses chondrocyte apoptosis. Hence, the gain- and loss-of-functions of $\beta$-catenin cause chondrocyte maturation and apoptosis, both of which are essential processes for endochondral ossification. The produced proteinases cause cartilage degradation at the center of the articular cartilage, where endochondral ossification remains incomplete due to insufficient vascular supply from the edge. Meanwhile, at the periphery of the articular cartilage, vascularity is accessible from synovium or tendon, so that endochondroal ossification is completed and osteophytes are formed. maturation and apoptosis. Although further human genomic and clinical studies are needed to elucidate the influence of the molecules on the pathogenesis of osteoarthritis, they might become therapeutic targets altering the course of this disabling disease. In addition, since serum levels of sFRP- 3 and Dkk1, secreted antagonists of the Wnt- $\beta$ catenin signal, are known to be associated with the radiographic joint space narrowing, [44] the molecules might be surrogate markers for cartilage loss during osteoarthritis progression.

\section{References}

1. Hunter DJ, Felson DT (2006) Osteoarthritis. BMJ 332: 639-642. [Crossref]

2. Sharma L, Kapoor D (2007) Epidemiology of osteoarthritis. In, Moskowitz RW Altman RD Hochberg MC Buckwalter JA Goldberg VM editors Osteoarthritis, Diagnosis and Medical/Surgical Management. 4th ed Philadelphia, Lippincott Williams \& Wilkins pp 3-pp26.

3. Yelin E, Callahan LF (1995) The economic cost and social and psychological impact of musculoskeletal conditions. National Arthritis Data Work Groups. Arthritis Rheum 38: 1351-1362. [Crossref]

4. Little CB, Meeker CT, Golub SB, Lawlor KE, Farmer PJ, et al. (2007) Blocking aggrecanase cleavage in the aggrecan interglobular domain abrogates cartilage erosion and promotes cartilage repair. J Clin Invest 117: 1627-1636.

5. Glasson SS, Askew R, Sheppard B, Carito B, Blanchet T, et al. (2005) Deletion of active ADAMTS5 prevents cartilage degradation in a murine model of osteoarthritis. Nature 434: 644-648. [Crossref]

6. Stanton H, Rogerson FM, East CJ, Golub SB, Lawlor KE, et al. (2005) ADAMTS5 is the major aggrecanase in mouse cartilage in vivo and in vitro. Nature 434: 648-652. [Crossref]

7. Burrage PS, Brinckerhoff CE (2007) Molecular targets in osteoarthritis: metalloproteinases and their inhibitors. Curr Drug Targets 8: 293-303. [Crossref]

8. Nagase H, Visse R, Murphy G (2006) Structure and function of matrix metalloproteinases and TIMPs. Cardiovasc Res 69: 562-573. [Crossref]

9. Li Y, Xu L, Olsen BR (2007) Lessons from genetic forms of osteoarthritis for the pathogenesis of the disease. Osteoarthritis Cartilage 15: 1101-1105. [Crossref]

10. Xu L, Peng H, Wu D, Hu K, Goldring MB, et al. (2005) Activation of the discoidin domain receptor 2 induces expression of matrix metalloproteinase 13 associated with osteoarthritis in mice. J Biol Chem 280: 548-555. [Crossref]

11. Xu L, Peng H, Glasson S, Lee PL, Hu K, et al. (2007) Increased expression of the collagen receptor discoidin domain receptor 2 in articular cartilage as a key event in the pathogenesis of osteoarthritis. Arthritis Rheum 56: 2663-2673. [Crossref]

12. Vincenti MP, Brinckerhoff CE (2002) Transcriptional regulation of collagenase (MMP-1 MMP-13 genes in arthritis integration of complex signaling pathways for the recruitment of gene-specific transcription factors. Arthritis Res 4: 157-164. [Crossref]

13. Clements KM, Price JS, Chambers MG, Visco DM, Poole AR, et al. (2003) Gene deletion of either interleukin-1beta, interleukin-1beta-converting enzyme, inducible nitric oxide synthase, or stromelysin 1 accelerates the development of knee osteoarthritis in mice after surgical transection of the medial collateral ligament and partial medial meniscectomy. Arthritis Rheum 48: 3452-3463. [Crossref]

14. Yamakawa K, Kamekura S, Kawamura N, Saegusa M, Kamei D, et al. (2008) Association of microsomal prostaglandin E synthase 1 deficiency with impaired fracture healing, but not with bone loss or osteoarthritis, in mouse models of skeletal disorders. Arthritis Rheum 58: 172-183. [Crossref]

15. Manabe N, Oda H, Nakamura K, Kuga Y, Uchida S, et al. (1999) Involvement of fibroblast growth factor-2 in joint destruction of rheumatoid arthritis patients. Rheumatology (Oxford) 38: 714-720. [Crossref]

16. Von der Mark K, Kirsch T, Nerlich A, Kuss A, Weseloh G, et al. (1992) Type X collagen synthesis in human osteoarthritic cartilage: indication of chondrocyte hypertrophy. Arthritis Rheum 35: 806-811. [Crossref]

17. Boos N, Nerlich AG, Wiest I, von der Mark K, Ganz R, et al. (1999) Immunohistochemical analysis of type-X-collagen expression in osteoarthritis of the hip joint. J Orthop Res 17: 495-502. [Crossref]

18. Pullig O, Weseloh G, Gauer S, Swoboda B (2000) Osteopontin is expressed by adult human osteoarthritic chondrocytes: protein and mRNA analysis of normal and osteoarthritic cartilage. Matrix Biol 19: 245-255. [Crossref] 
19. Pullig O, Weseloh G, Ronneberger D, Kakonen S, Swoboda B (2000) Chondrocyte differentiation in human osteoarthritis: expression of osteocalcin in normal and osteoarthritic cartilage and bone. Calcif Tissue Int 67: 230-240. [Crossref]

20. Pfander D, Swoboda B, Kirsch T (2001) Expression of early and late differentiation markers (proliferating cell nuclear antigen, syndecan-3, annexin VI, and alkaline phosphatase) by human osteoarthritic chondrocytes. Am J Pathol 159: 1777-1783. [Crossref]

21. Takeda S, Bonnamy JP, Owen MJ, Ducy P, Karsenty G (2001) Continuous expression of Cbfa1 in nonhypertrophic chondrocytes uncovers its ability to induce hypertrophic chondrocyte differentiation and partially rescues Cbfa1-deficient mice. Genes Dev 15: 467-481. [Crossref]

22. Ueta C, Iwamoto M, Kanatani N, Yoshida C, Liu Y, et al. (2001) Skeletal malformations caused by overexpression of Cbfa1 or its dominant negative form in chondrocytes. $J$ Cell Biol 153: 87-100. [Crossref]

23. Kamekura S, Hoshi K, Shimoaka T, Chung U, Chikuda H, et al. (2005) Osteoarthritis development in novel experimental mouse models induced by knee joint instability. Osteoarthritis Cartilage 13: 632-641. [Crossref]

24. Kamekura S, Kawasaki Y, Hoshi K, Shimoaka T, Chikuda H, et al. (2006) Contribution of runt-related transcription factor 2 to the pathogenesis of osteoarthritis in mice after induction of knee joint instability. Arthritis Rheum 54: 2462-2470. [Crossref]

25. Koshizuka Y, Yamada T, Hoshi K, Ogasawara T, Chung U, et al. (2003) Cystatin 10 a novel chondrocyte-specific protein may promote the last steps of the chondrocyte differentiation pathway. J Biol Chem 278: 48259-48266. [Crossref]

26. Yamada T, Kawano H, Koshizuka Y, Fukuda T, Yoshimura K, et al. (2006) Carminerin contributes to chondrocyte calcification during endochondral ossification. Nat Med 12: 665-670. [Crossref]

27. Kühn K, D'Lima DD, Hashimoto S, Lotz M (2004) Cell death in cartilage. Osteoarthritis Cartilage 12: 1-16. [Crossref]

28. D'Lima D, Hermida J, Hashimoto S, Colwell C, Lotz M (2006) Caspase inhibitors reduce severity of cartilage lesions in experimental osteoarthritis. Arthritis Rheum 54: 1814-1821. [Crossref]

29. Shimizu S, Asou Y, Itoh S, Chung UI, Kawaguchi H, et al. (2007) Prevention of cartilage degradation with intraarticular osteoclastogenesis inhibitory factor/osteoprotegerin in a murine model of osteoarthritis. Arthritis Rheum 56: 3358-3365. [Crossref]

30. Glass DA 2nd, Karsenty G (2007) In vivo analysis of Wnt signaling in bone Endocrinology 148: 2630-2634. [Crossref]

31. Day TF, Guo X, Garrett-Beal L, Yang Y (2005) Wnt/beta-catenin signaling in mesenchymal progenitors controls osteoblast and chondrocyte differentiation during vertebrate skeletogenesis. Dev Cell 8: 739-750. [Crossref]
32. Tamamura Y, Otani T, Kanatani N, Koyama E, Kitagaki J, et al. (2005) Developmenta regulation of Wnt/beta-catenin signals is required for growth plate assembly, cartilage integrity, and endochondral ossification. J Biol Chem 280: 19185-19195. [Crossref]

33. Yano F, Kugimiya F, Ohba S, Ikeda T, Chikuda H, et al. (2005) The canonical Wnt signaling pathway promotes chondrocyte differentiation in a Sox9-dependent manner. Biochem Biophys Res Commun 333: 1300-1308. [Crossref]

34. Diarra D, Stolina M, Polzer K, Zwerina J, Ominsky MS, et al. (2007) Dickkopf-1 is master regulator of joint remodeling. Nat Med 13: 156-163. [Crossref]

35. Loughlin J, Dowling B, Chapman K, Marcelline L, Mustafa Z, et al. (2004) Functiona variants within the secreted frizzled-related protein 3 gene are associated with hip osteoarthritis in females. Proc Natl Acad Sci U S A 101: 9757-9762. [Crossref]

36. Lane NE, Lian K, Nevitt MC, Zmuda JM, Lui L, et al. (2006) Frizzled-related protein variants are risk factors for hip osteoarthritis. Arthritis Rheum 54: 1246-1254. [Crossref]

37. Min JL, Meulenbelt I, Riyazi N, Kloppenburg M, Houwing-Duistermaat JJ, et al (2005) Association of the frizzled-related protein gene with symptomatic osteoarthritis at multiple sites. Arthritis Rheum 52: 1077-1080. [Crossref]

38. Kim SJ, Im DS, Kim SH, Ryu JH, Hwang SG, et al. (2002) Beta-catenin regulates expression of cyclooxygenase-2 in articular chondrocytes. Biochem Biophys Res Commun 296: 221-226. [Crossref]

39. Hwang SG, Yu SS, Ryu JH, Jeon HB, Yoo YJ, et al. (2005) Regulation of beta-catenin signaling and maintenance of chondrocyte differentiation by ubiquitin-independent proteasomal degradation of alpha-catenin. J Biol Chem 280: 12758-12765. [Crossref]

40. Corr M (2008) Wnt-beta-catenin signaling in the pathogenesis of osteoarthritis. Nat Clin Pract Rheumatol 4: 550-556. [Crossref]

41. Schett G, Zwerina J, David JP (2008) The role of Wnt proteins in arthritis. Nat Clin Pract Rheumatol 4: 473-480. [Crossref]

42. Zhu M, Tang D, Wu Q, Hao S, Chen M, et al. (2009) Activation of B-catenin signaling in articular chondrocytes leads to osteoarthritis-like phenotype in adult $\beta$-catenin conditional activation mice. J Bone Miner Res. [Crossref]

43. Zhu M, Chen M, Zuscik M, Wu Q, Wang Y, etal. (2008) Inhibition of B-catenin signaling in articular chondrocytes results in the development of osteoarthritis. Arthritis Rheum 58: 2053-2064. [Crossref]

44. Lane NE, Nevitt MC, Lui LY, de Leon P, Corr M, et al. (2007) Wnt signaling antagonists are potential prognostic biomarkers for the progression of radiographic hip osteoarthritis in elderly Caucasian women. Arthritis Rheum 56: 3319-3325. [Crossref]

Copyright: (C2016 Kawaguchi H. This is an open-access article distributed under the terms of the Creative Commons Attribution License, which permits unrestricted use, distribution, and reproduction in any medium, provided the original author and source are credited. 